This item was submitted to Loughborough's Research Repository by the author.

Items in Figshare are protected by copyright, with all rights reserved, unless otherwise indicated.

\title{
Exploring the registers of identity research
}

PLEASE CITE THE PUBLISHED VERSION

https://doi.org/10.1111/ijmr.12149

\section{PUBLISHER}

Wiley @ British Academy of Management and Wiley

\section{VERSION}

AM (Accepted Manuscript)

\section{PUBLISHER STATEMENT}

This work is made available according to the conditions of the Creative Commons Attribution-NonCommercialNoDerivatives 4.0 International (CC BY-NC-ND 4.0) licence. Full details of this licence are available at: https://creativecommons.org/licenses/by-nc-nd/4.0/

\section{LICENCE}

CC BY-NC-ND 4.0

\section{REPOSITORY RECORD}

Corlett, S., P. McInnes, Christine Coupland, and M. Sheep. 2019. "Exploring the Registers of Identity Research". figshare. https://hdl.handle.net/2134/25377. 
Corlett, S., Mclnnes, P., Coupland, C. and Sheep, M. (forthcoming) Exploring the registers of identity research. International Journal of Management Reviews IJMR17-0075. Special Issue

Keywords: identity, registers, theoretical traditions, levels of identity, methodologies

\begin{abstract}
As the lead, introductory, contribution to this special issue 'exploring registers of identity research', this paper offers a view of three different "registers" that might be seen to characterize identity research and which feature, to a greater or lesser extent, in the selected papers. First, the paper offers a means to understand the different theoretical traditions used to explain what constitutes identity and how it might be known. Second, it considers the relationship between different levels of identityindividual, group, professional, organizational, and societal. Third, it reviews the methodologies used to understand identities and examines key theoretical assumptions which feature in academic debates, and in the selected papers, around identity theorizing. Drawing on the papers included in this special issue we offer a framework as a heuristic device that might guide scholars looking to enter the field of identity research and enable those already familiar with particular theoretical traditions, levels, or methods to explore possibilities for extending their research. As enticement to tackle the challenges extension across-registers can present, we again turn to the special issue articles to examine - through a series of 'gets' - the different tactics authors might use to access the rich potential offered by crossfertilization between registers. Our contribution then lies in advancing the potential for dialogue between registers of identity research.
\end{abstract}




\section{Exploring the registers of identity research}

\section{Introduction}

As originally conceived, this special issue was intended to provide a broad-based review of where research on identity within organizations had reached and, in acknowledging the different traditions from which this research is undertaken, explore the potential for these to inform future efforts. To this end we introduced the term 'registers of identity' to suggest the potential for harmony (in the sense of different vocal registers coming together), while also connoting the discrete disciplines (in the sense of bureaucratic registers of formal records) in which scholarship proceeds. The papers within this special issue can certainly be said to inform our understanding of the latter, and this paper builds on this in order to consider the former. Specifically, this paper offers a framework that may act as a heuristic device to help scholars conceptualize and theorize identity, and to appreciate the potential intersections of different theoretical traditions at different levels of identity - individual, group, professional, organizational and societal. The significance of this framework, and its discussion of associated research methodologies and methods, lies in providing a more holistic interpretation of the identity field. It may, then, facilitate exploration of the potential - where it exists - for cross-fertilization between theoretical traditions, levels, and methods. Theexpressed, but ultimately unfulfilled, aspiration of the selected papers to achieve dialogue leads us to reflect on our desire for harmony within and across different registers. Appropriating from the work of Roland Barthes, we suggest that our aspiration to encourage harmony might miss the generative potential of engaging with the 'enigma' posed by the otherness of and persistent tensions within each register. The future of identity studies, then, might not so much be dialogue between registers, as critically engaging with the assumptions which constitute our own.

\section{Setting the context - The special issue call and selected papers}

The study of individual and organizational identities has attracted much research interest in management and organization studies (MOS), with special issues being compiled by Academy of Management Review (2000), Organization (2008), Human Relations (2009), and Scandinavian Journal of Management (2012) and review papers being published by IJMR (Winkler 2016; Brown 2015; Ravasi and Canato 2013). In furthering IJMR links to the British Academy of Management (Jones and Gatrell 2014), the motivation for this special issue came in response to multiple and repeated requests from identity scholars attending the BAM Identity special interest group conference track to have guidance for entering a complex field. The intended audience for this special issue included early career researchers, doctoral students who are about to undertake an identity research project and experienced researchers who are interested in exploring alternative identity theories for their research interests. Therefore, we intend that the special issue provides these groups with an understanding of the diversity of the field. 
In the call for special issue papers (Corlett et al. 2015), we proposed that submissions might consider the potential to advance understanding of the productive possibilities (and impossibilities) of working across different theoretical traditions of identity research and across or at multiple levels of identity. Furthermore, we called for papers to consider the potential opportunities of 'borrowing' data collection and analysistools from different traditions to enrich identity studies. Our proposed framing of different theoretical traditions included: social identity and self-categorisation theories; cognitive and sensemaking approaches informed by the American pragmatist tradition; and identity work, including narrative and poststructural critical theory perspectives. Each of the selected papers responds to the call and, in different ways, provides insight into the diversity of the field of identity scholarship. In the following paragraphs, we introduce the papers and their emphases in terms of theoretical traditions, levels, and methods.

Atewologun, Kutzer, Doldor, Anderson and Sealy, in their paper "Individual-level foci of identification at work: A systematic review of the literature", identify the diverse bases, or foci, by which individuals construct particular identities in the work context. The individual-level identification foci include self-other relationships, such as manager, leader, follower, and self-collective relationships, such as team, organization, and occupational or professional group. After proposing construct clarity and integrative definitions, in relation to various theoretical traditions, Atewologun et al. offer an integrative framework to enable scholars to position work in the identity field.

Brown, in "Identity work and organizational identification", examines the relationships between the burgeoning identity work literatures with the more long-standing research on identification. Therefore, like Atewologun et al., Brown's emphasis is directed toward individual-level identity, as considered in tandem with organizational identification, that is 'ways people draw on their membership of organizations in their constructions of self' ( $p$. 1). From an extensive review of identity, identity work, and identification literature, Brown describes five approaches through which identities and identification processes are constituted. Two of these are most aligned with a cognitive/pragmatist tradition - the socio-cognitive approach (where identity and identification are constituted through cognitive mechanisms and/or sensemaking) and the psychodynamic approach (where they are constituted through the operation of unconscious ego defences). The three remaining approaches described most align with a more fluid and agential view of how identities are accomplished and negotiated as 'identity work' and 'identification work'. They are: a discursive approach, which investigates how situated practices of language use dynamically constitute identities and identification; a dramaturgical approach, which focuses on the way in which actions or 'performances of the self' accomplish the same and; a symbolic approach, which examines how identity/identification work is accomplished 
'through the adoption, display and manipulation of object symbols' (Brown 2017, p. 13).

Haslam, Cornelissen, and Werner, in "Metatheories and metaphors of organizational identity: Integrating social constructionist, social identity, and social actor perspectives within a social interactionist model", present a review of theories of organizational identity on a meta-level and explore three traditions of identity research in order to integrate the perspectives. Social constructionist (including a cognitive variant based on Weick $(1995,1979)$ and sensemaking more broadly), social identity and social actor 'metatheories' are contrasted along particular lines in order to discuss a social interactionist model. In the paper the social constructionist perspective allows for both a cognitive frame of reference and a discursive frame of reference. Haslam et al. discuss clusters of research approaches which have similarities and, perhaps more importantly for considering where identity research may focus in the future, the degrees to which they differ currently but offer potential to be combined for richer explanations of organizational identity.

Knights and Clarke, in "Pushing the boundaries of amnesia and myopia: A critical review of the literature on identity in Management and Organization Studies", argue that identity scholars might develop their analyses further by looking backwards to past literatures and sideways to a more diverse range of present literatures from other disciplines which employ different terminologies around identity. Through their provocative stance and reflective analyses of historical contributions and broader conceptualizations of identity, they challenge individualistic and narcissistic 'preoccupations with, and attachment to, identity' in order to 'acknowledge that our embodied and ethicalrelationships with one another need not be just about us' (Knights and Clarke 2017, p. 4, emphasis in original). As part of their argument, in acknowledging identity as embodied and material practices, the authors take up the special issue's call 'to look beyond "talk" to examine the literature and future direction that studies of embodied performance of identity might take' (Corlett et al. 2015, p.411).

Beech, in "Identity at Work: An enquiry-based approach to therapeutically-inspired management", contributes an invited dialogue piece which focuses on an enquiry response to identity problems in the workplace. It draws together problems identified at societal, organisational and inter-personal levels in the management and organization studies (MOS) literature and poses the question of how managers could respond to such problems. The paper then develops a dialogue between MOS and psychotherapeutic theories to reframe the management problems.

Psychotherapeutic theories, and particularly a pluralistic approach (Cooper and McLeod, 2010), open up possibilities for management practice beyond those contained in the MOS literature. This reframing is then used to offer a contribution back to the MOS literature and management practice by developing a route for new ways of thinking about: establishing the environment for performance; enabling a 'thinning of the plot and thickening of the counter-plot' and; developing coaching and 
self-coaching as a core social structure of the organisation. Thus, there is crossfertilization between two fields, drawn together by a shared interest in understanding and taking action on identity problems. There is also an interplay between the individual, inter-personal and organisational levels in action. In common with the idea of 'exploring the registers', Beech proposes a dialogical enquiry, structured by action-oriented questions with theories providing insight as a resource for action.

\section{Registers of identity research - a heuristic framework for understanding identity scholarship}

Having considered each of the papers, we turned to the question of how we might understand and relate the diverse contributions to this special issue. As we signalled earlier, our intention with this special issue was to bring about what Alvesson et al. $(2008$, p. 9) termed 'a more engaged conversation across metatheoretical lenses'. In their own ways the contributions press towards this. Haslam et al., for example, utilise three metaphors - framing, categorization and personification - to demonstrate underlying assumptions behind and beneath (using 'deeper' metaphor) their three identified perspectives and as a way of 'seeing' how research from each perspective has been approached. Similarly, Knights and Clarke challenge scholars not only to push beyond amnesic and myopic tendencies, which fail to take into account historical and other disciplines' alternative understandings of identity, but also urge them, in writing about identity and identity work, to 'interrogate the underlying assumptions rather than reproducing them' (p. 34). Brown concentrates on forms of identity work that enact social identification with an organization, group or profession in order to compare the ways in which the lenses of the five approaches (discursive, dramaturgical, symbolic, socio-cognitive, and psychodynamic) both differ and overlap. Indeed, Brown goes a step further to say that presenting the five approaches separately is only for the sake of simplicity, and that they are "best understood not just as intimately linked and to some extent overlapping, but as collectively constituting a particular "perspective" on identity processes' (p. 25). Atewologun et al. draw on Alvesson et al. (2008) to argue that lack of clarity about the constructs of identity precludes dialogue across different meta-theoretical perspectives and propose, using Suddaby (2010), that such clarity and 'shared meaning' will lead to 'richer and deeper understanding in the field' (pp. 3-4).

Thus, from our reading of the papers' analyses and arguments we developed a heuristic framework (Figure 1) as a potentially useful way for researchers new to the field of identity research to engage in conversations with identity research scholars. In addition, for experienced identity researchers who are interested in expanding their research projects in different directions theoretically and practically, we hope it also has some utility, for instance in conversing across levels of identity scholarship and theoretical traditions. We next discuss Figure 1 by referring to each of the papers. 
In explaining the individual-level focus of their paper, Atewologun et al. (p.7) draw on the work of Cornelissen et al. (2007) who 'differentiate identity research in the organizational domain as individual (relating to people's personal sense of self within the organization), group (relating to the shared identity of teams and sections within an organization), organizational (relating to the identity of the organization as a whole) and cultural (relating to commonalities in identity across organizations and within a society)'. In the heuristic framework we depict these differentiations, or'registers', as four 'levels of identities'. In keeping with Knights and Clarke's (this issue, p. 60) argument that 'identities only exist when they are interacting such that the relationship between conceptions of a seemingly discrete 'self' and wider 'society' is rather an unrelenting, inter and intra-dependent, co-constituting phenomenon (Barad 2007)', we have denoted particular levels of identities as interconnected and overlapping.

Nested within and across considerations of levels of identity, our heuristic framework depicts a further two registers, considered by the authors, concerning metatheoretical and theoretical traditions. In terms of what we are describing as metatheoretical traditions, or broad ontological and epistemological questions of what constitutes identity and how it is understood, Atewologun et al. categorize their selected literature using Alvesson et al.'s (2008) typology of functionalist, interpretivist, and critical orientations, complemented by Brown's (2015) inclusion of the psychoanalytic orientation. Their review suggests that scholars from different meta-theoretical traditions tend to work 'in isolation' (Atewologun et al. this issue, p. 23) and draw on particular theoretical traditions. For example, they discuss how scholars adopting: a functionalist orientation generally understand identity as a socio-cognitive construct (Brown 2015, and this issue); an interpretivist orientation have a 'meaning-centred focus' ( $p .23$ ) and employ discursive and symbolic (interactionist) theories (Brown 2015, and this issue) and; a critical orientation focus on power relations using post-structuralism. They also refer to Brown's (2015) classification of a psychoanalytic orientation, drawing on European theorists such as Jacques Lacan and Sigmund Freud, which Brown (this issue) relates to psychodynamic identity work. Knights and Clarke (this issue) argue that the dominance of discursive and symbolic understandings of identity have led to a neglect of embodied notions of identity and the importance of exploring 'identity in relation to our embodied engagement with others' (p. 72). They discuss how studies largely outside of MOS identity literature are remedying 'the absent body' by drawing on ideas, in part, from posthumanist feminism. Within our heuristic framework we have shown meta-theoretical traditions, including psychoanalytic, functionalist, interpretivist, critical, and posthumanist feminist, as sometimes overlapping registers, and as interconnected with particular theoretical traditions, as further 'registers'. We elaborate further, in the following paragraphs, on the positioning, within this framework, of particular meta-theoretical traditions in relation 


\section{Figure 1: Registers of Identity}

\section{Levels of identities}

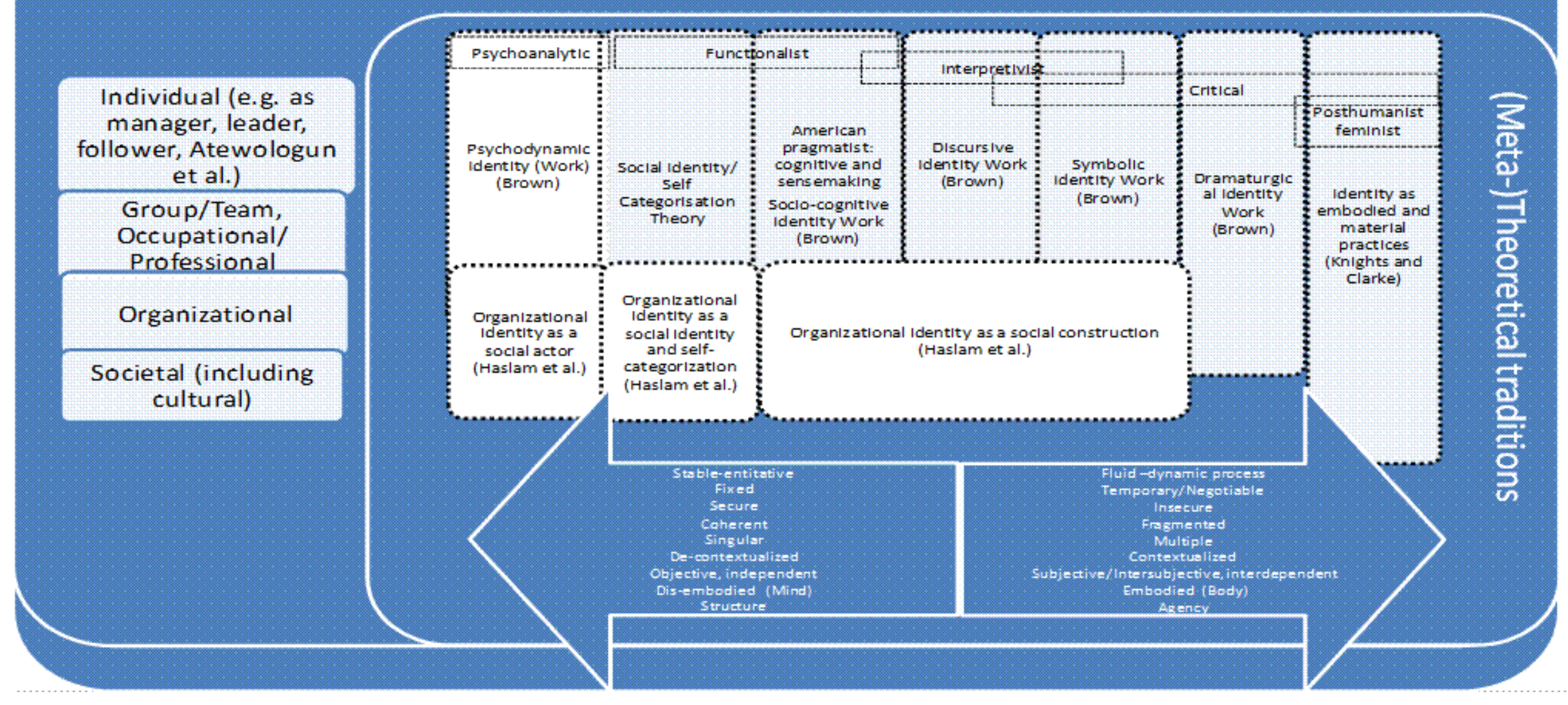


to associated theoretical traditions by drawing on the authors' analyses and arguments in the special issue papers.

Brown (this issue) analyses five interrelated approaches - psychodynamic, sociocognitive, discursive, symbolic and dramaturgical - to identity work and organizational identification by which individuals construct their selves in relation to their organizations. He proposes that the five approaches and forms of identity work associated with them are overlapping and interlinked, which we have suggested diagrammatically by the dotted line framing each approach. Brown connects individual-level identity work processes and organizational-level identification and argues that "phenomena referred to under the umbrella "organizational identification" are best regarded as processes of identity work (p. 2). Following this proposition, in reading Figure 1 from top to bottom, we have positioned individual-level identity as a higher register than, say, organizational-level identity. Furthermore, Brown suggests that empirical research engaging in a deliberate way with the five approaches might encourage 'more broad-ranging theorizing' and 'greater appreciation of the multifaceted, interconnected ways in which identities are worked on and identification enacted' (p. 12).

In the framework, we have related four of Brown's identity work and organizational identification approaches to the three dominant theoretical traditions informing organizational identity research identified by Haslam et al. (this issue). Haslam et al. explain that their first identified theory, organizational identity as a social construction, focuses attention on 'shared narratives, or cognitive schemes that members collectively construct to give meaning to their shared experience' ( $p .7$ ). Because of its interest in both the products and processes of social construction - that is, how language, symbols, and materials shape and produce people's cognitive sensemaking - we have related Haslam et al.'s social constructionist tradition to Brown's socio-cognitive, discursive and symbolic identity work processes. Haslam et al.'s second identified theory, organizational identity as a social identity and selfcategorization, relates to the theoretical tradition of the same name we discussed within the special issue call. We have related Haslam et al.'s third identified theory, organizational identity as a social actor, to Brown's psychodynamic identity work approach. We acknowledge that social actor theory scholars may explore how organizational identity is 'symbolically constructed through commitments, public statements, and legitimating claims' (Haslam et al. p. 16) and, thus, interrelates with Brown's discursive and symbolic identity work approaches. However, such commitments and communications are 'compressed' into a theory of the organization as a single actor (Haslam et al. 2007, p. 20). Furthermore, Haslam et al. explain how social actor theory is also consistent with a psychodynamic approach to organizational identity, particularly when the organization is understood to be dysfunctional and pathological. Similar to Brown's view of the overlapping nature of the five approaches to identity work and organizational identification, Haslam et al. consider the boundaries between the three theories as 'rather fuzzy and permeable' 
(p. 24), which we have attempted to convey by the overlapping, dotted line shapes denoting the different theoretical traditions.

Knights and Clarke argue that 'the body and other aspects of materiality are significant by their absence (Knights 2015)' and few identity studies 'provide an embodied analysis of identity where mind and body are inseparable' (p. 74). They urge identity scholars to revisit earlier literature (e.g. Watts 1966) and to draw on posthumanist feminist ideas (e.g. Butler 1993; Barad 2007; Braidotti 2011; Pullen and Rhodes 2014) to theorize identity not only as discursive and symbolic, but also as embodied andmaterial. In reflecting on the question of 'how can the individual be anything other than social?', Knights and Clarke point to the 'potentially dangerous' implications of 'reinforcing this artificial separation between the two' and '(albeit unconsciously) legitimis[ing] the individual in privileging his/herself over society' ( $p$. 84). As posthumanist feminist-informed understandings of identity, as embodied and material practices, seek to "illuminate relationships between the body, self, society and culture' (Wainwright and Turner, 2006b, p.238/240)"' (Knights and Clarke, p. 26), we have denoted, in Figure 1, this meta-theoretical and related theoretical tradition as encompassing individual and societal levels of identity.

The papers that make up this special issue highlight debates relating to theoretical assumptions, which we interpret as further illustrations of registers that have long featured in identity research. From the time of the first major book on organizational identity (Whetten and Godfrey 1998), attempts have been made to describe how identity looks from a variety of perspectives. Corley et al. (2006, p.87) grouped much of the organizational identity literature along ontological dimensions of 'phenomenon versus metaphor' and 'essence versus socially constructed'. Our heuristic framework also conveys, by the diverging arrows', a more nuanced parsing of debates, or registers, about the nature of identity (and identification processes), which emerge from the papers. Broadly, the arrows point toward a positivist, objectivist view of identity on the left extreme and to a constructionist, subjectivist/ intersubjectivist view of identity toward the right extreme. Of course, that is an oversimplification, as there are views between the two extremes that allow for elements of both held in tension or integrated, or variations of each, rather than suggesting these are mutually exclusive, binary opposites - or even an exhaustive list.

In Figure 1, we acknowledge theoretical assumptions reviewed in the papers as mapped along dimensions of stable-entitative vs. fluid-dynamic and evolving process (Atewologun et al.; Brown; Knights and Clarke; Haslam et al.), fixed vs. temporary and negotiable (Atewologun et al.; Brown; Haslam et al.), secure vs. insecure (Knights and Clarke), coherent vs. fragmented (Brown), singular vs. multiple (Atewologun et al.; Brown), de-contextualised vs. contextualised (Atewologun et al.), objective vs. subjective (Brown; Haslam et al.), independent vs.

dependent/interdependent (Haslam et al.; Knights and Clarke) and dis-embodied vs. embodied (Knights and Clarke), and structure vs. agency (Brown; Haslam et al.). For example, Brown contrasts the implications, in relation to the stable-entitative and 
fluid-dynamic process debate, of understanding identification as a noun and as a verb. Similarly, Atewologun et al. incorporate the debate of stable or evolving identity construction as an axis in their integrative framework. They propose that a central difference in scholarship revolves around a 'variance approach' to identities and a process understanding of identification, which again relates back to understanding identification as a noun or verb. Knights and Clarke also engage with notions of identity stability and security, and argue that attempts to secure a stable identity are self-defeating because 'by virtue of its construction, identity is inherently precarious and ephemeral because of its dependence on the unpredictable and uncontrollable social confirmation of others' (Knights and Clarke 2017, p. 52).

In their review, Haslam et al. explain how the degree of contextual sensitivity differs according to theoretical stance: social constructionists identify local and specific uses of labels about organizations; social identity is described as less contextually sensitive as social identities are understood across organizations as relatively stable internalised cognitive structures or categories and; social actor theory is most strongly de-contextualised as the primary focus has been upon stable and persistent features of organizations over time. In a similar vein, Atewologun et al. incorporate research interest focus on context - or situational, social and historical - factors shaping identity (contrasted with a focus on identity 'content') as the vertical axis in their proposed integrative framing of the literature.

A further dimension of difference which has been identified by Haslam et al. is that of the status of organizational identity as objective or subjective. As might be expected, social constructionist theory research employs, in the main, subjective and intersubjective meanings to understand organizational identities. Social identity research contrasts in that, although self-categorization may be regarded as a subjective process, social identities come to assume the status of objective, prototypical categories. Social actor theorizing casts the category of the organization as outside and independent of the members of the organization and hence organizational identity is regarded as having material reality. What could bedeveloped further from this argument is the degree to which each of the approaches is able to deal with fractures and fissures in what organizational identity is purported to be and how the members continuously challenge and disorientate what may once have been perceived as stable. Brown raises the 'fractured' and 'multiple' nature of organizational 'identifications' as empirical issues. That is, how can researchers select most productively among the five approaches he identifies to research 'various organizational, managerial, professional, generational and occupational identities' as well as their concomitant identifications (that may vary widely as dis-identification, schizo-identification, and so on) (Brown this issue, p. 32).

In relation to a further debate in the literature, that of structure and agency, Brown suggests that discursive, dramaturgical and symbolic identity work processes are more likely to be associated with individual agency, while SIT/SCT and psychodynamic approaches 'highlight the extent to which people are prisoners of 
their psychology' (p. 30). Knights and Clarke (this issue) claim that the psychoanalytic approach (for instance of Lacan 1980, 2008) challenges the notion of self as autonomous. This is because psychoanalytic theory 'is predicated on ideas of unconscious forces and desires that often leave the subject unaware, and thereby incapable of controlling their emotions, fantasies and actions' (Knights and Clarke 2017, p. 63). However, despite Lacan's critique of autonomy, 'psychoanalysis can itself serve to repress subjects through reproducing processes of normalisation, by standardising a set of behaviours' (Knights and Clarke this issue, p. 63). Haslam et al. also comment on the focus on agency across the three theories of organizational identity they identify and note that the social constructionist perspective 'emphasizes agency and choice in the way that members (re)negotiate shared interpretations about the nature of their organization and the meaning of its identity claims (Gioia et al., 2013, p 160)' (p. 26).

Whilst we offer Figure 1 as a heuristic framework, we acknowledge that the framework may be prone to 'risk of reductionism' (Alvesson et al. 2008, p. 11) and to accusations of misrepresentation. We appreciate that the framework's value depends on the meta-theoretical tradition of the reader (Alvesson, Hardy and Harley 2008). Applying the illustrations given by Alvesson et al. (2008), readers from a functionalist tradition may regard the framework as a more or less accurate representation of the field of identity. Interpretivist readers may not share the functionalist concern about the accuracy of the framework and may be more interested in whether and how it is used. Critical readers may resist the production of the framework altogether, arguing that we have exercised authorial privilege and objectified the phenomenon. However, we hope the framework may be of practical use in providing 'a point of entry into a complex field' (Smith and Sparkes 2008, p.7) and in enabling identity scholars to position their own and others' particular temporally- and historically-situated studies.

\section{Between registers of identity research: Methodologies/Methods}

Emerging from our analysis of the special issue's papers, the heuristic framework is useful in framing the different languages which identity researchers use. Of course it is not just the specific meanings of particular terms that prevent discussion, perhaps, as Ravasi and Canato (2013) argue, it is the epistemological question of what is taken as evidence of identity which might emerge as a continuing discussion for identity scholarship. Accordingly we now turn to examine the papers' consideration of methodologies and methods that researchers have used to understand and investigate identities.

Brown's paper outlines five approaches to identity work not only to demonstrate how they inform theory but also to illustrate how they guide empirical work around how people relate to social categories which he calls identification work. Within and among these five, debates centre on whether identity work denotes a construct, concept metaphor, a perspective, or a combination of these. He argues that 
uncertainty arises due to a lack of clarity around the phrase identity work in both theorising and empirical studies. For instance, Brown explains that while SIT/SCTinformed research tends to use experimental and survey techniques, 'other approaches lend themselves to interpretive methodologies using mainly, though not necessarily exclusively, qualitative methods.... The employment of these methods to expand the regime of truth associated with organizational identification scholarship may thus better assist efforts to author 'thick descriptions' (Geertz 1973) and to discover richness, depth, pluralism, and simultaneity as well as sequentiality' (p. 345). Thus, Brown calls for scholars to consider the different approaches as not necessarily providing a unified framework to understand identities and identifying, but rather as offering a perspective which is unified through concerns with agency and process issues.

Haslam et al. make clear that the choices researchers make about how to conceptualize the phenomena of interest are based, not surprisingly, on underlying assumptions about the world, the constructs and the presumed relationships that exist. Their contribution is to suggest that these function as metaphorical relationships which, in addition to other influences, give precedence to particular forms of activity (e.g. methods) through which the phenomena may be examined.

Knights and Clarke make a more robust call to expose and examine common sense understandings around identity in order to engage with the past and the multidisciplinary present while drawing upon practices of embodied engagement. They draw attention to methodological tunnel vision evidenced in empirical studies where the researcher's embodied experiences and concerns are not taken into account. Indeed they elevate interest in methodological concerns to the centre of their review article. Agency and process issues also feature in their review and approach to embodied agency as a non-negotiable aspect of identity.

Atewologun et al. re-iterate the point that, despite (or perhaps due to) a proliferation of concepts, a lack of consensus remains regarding how to conceptualize and empirically investigate work-related individual identities. Part of their review includes attention to the scope of interest and underlying assumptions demonstrated by researchers. They offer a framework that has potential to enable researchers to position their work conceptually and empirically in the field and identify prospective theoretical or methodological challenges therein.

It may be argued that multiple approaches to the study of identity work and organizational identification, once recognised for the plurality of insights they offer, represent the complexity of the phenomena which would not easily (nor is it desirable to) be rendered down to a single, preferred, form of investigation. Independently occurring conversations around how to study identity work and identification, through review pieces such as this, may be drawn into fruitful debates and future empirical work that should challenge what is familiar and provoke nuanced and novel insight. 


\section{Blending registers: Dialogue, or enrichment through the enigma posed by others?}

As became evident in the last section, establishing a harmonious dialogic engagement between and across registers of identity is far from straightforward. Brown neatly captures the quandary in his extended questioning of the venture: 'can studies of identity work and organizational identification which deliberately employ two or more of these approaches in tandem stimulate additional insights on identity and identification dynamics? Do some combinations of these approaches work better to elicit certain research findings than others? ... Which permit the most interesting and insightful studies of how identifications alter over time? Do some of these conceptions allow researchers more scope for accounting adequately for how contexts - different organizations, industries, cultures etc. - affect identity work and organizationalidentification processes? How might these multiple approaches best be used to explore how and why people become strong, weak, schizo-, neutral etc. identifiers with their organizations? Which permit the most fecund multi-level research?' (p. 27-8).

Should we, then, simply abandon the enterprise of engaging across registers? While wary of the pitfalls faced by the field, authors within and beyond the special issue consistently invoke the metaphor of 'myopia' to suggest how this might restrict what can be seen and discussed. Brown, for example, cautions researchers about the dangers of taking a myopic view, when discussing SIT/SCT theorising in identity and organizational identification research. Similarly, Coupland and Brown (2012) cautioned that 'identity studies may become overly myopic, introspective and detached from broader debates' (p. 2). Knights and Clarke, in this issue, also respond to this 'omnipresent danger' (Coupland \& Brown 2012, p. 2). They extend the metaphor of myopia and also of amnesia to encourage identity scholars to look beyond the disciplinary boundary of Management and Organization Studies (Gatrell and Breslin 2017) to see (again) and to be reminded of theoretical insights on the self from the multidisciplinary present and the historical past.

With this in mind, it is worth examining more closely what our contributors are suggesting as generative approaches by which we might grapple with the multiple languages that have spawned around the issue of identity. To do so, we propose analogies that we call 'get...' mechanisms - that is, how researchers might position their work (i.e., where they might move or 'get' theoretically/paradigmatically) to bridge, reconcile, compare, integrate (or not) across otherwise disparate registers of identity.

Get around it - This mechanism involves having a will to surmount disparity, not by correction, or compromise, but by finding ways in which to proceed. This sense of getting around the issues is something that to some extent all our authors are engaged in. Mostly clearly, and correctly given its status as a dialogue piece, Beech is doing just that as he weaves the positions of different authors - and the theorists 
that inform their work - into a narrative of the identity field. However, while informative, and deeply helpful, as a narration, it is a retrospective account. In attempting to move forward, our authors adopt more interventionist approaches.

Get above it (or below it) - The move here is to find a new unifying position from which different registers can speak on common ground (below) or transcendent terms (above). For example, this might involve an attempt to surmount the issues by constructing unifying frameworks (Atewologun et al.). However, identity scholars are all too aware of the commitments to which their position ties them, and it may well take a move - such as is taken by Knights and Clarke - to critically examine the conceptual foundations sustaining the discreteness of different registers in order to press the field to take on new challenges.

Get back - Responding to the accusation that the field exhibits 'a lack of concern to look either backwards or sideways, such that the peripheral vision potentially afforded by the past and other disciplines is lost' (p. 3) the paper by Knights and Clarke exemplifies the approach of those seeking progress through broadening and deepening scholarship in established academic traditions. Hence they entreat the community to 'get back' to theoretical schools that have given fulsome consideration to areas of current controversy, or indeed may serve as a basis for identifying where next for the field.

Get together - That is, finding a new way that we can agree upon and coexist within a particular encounter and in future encounters. For example, Haslam et al. are optimistic researchers on organizational identity will come to recognise that their identified perspectives probably, in practice, differ in degrees of shades of emphasis. They also suggest a shared view of the importance of looking at processes of identities as fluid, shared (to a degree), managed (to a greater or lesser extent) and look to a future direction in which scholars seek to understand the conditions in which particular forms of identities prevail.

Get along - In many ways related to the previous category, some advocate allowing co-existence amongst the diversity of approaches. For example, Brown argues that viewing the five approaches he articulates as a whole 'allows us better to appreciate their commonalities and potential synergies, not merely their disjunctures and differences. In particular, it encourages recognition of how each approach is as much concerned with embedded actors and their actions as they are the outcomes of those actions' (p. 25).

Get through it (or get over it) - Contrasting with the accommodative tone of 'get together' and 'get along' are suggestions of a more muscular insistence that we should just work through the difficulties, getting over the issues, or perhaps more fittingly getting over ourselves. Given the symbolic violence it inflicts, moves to 'get through it' are typically implicit to attempts to downplay difference in advancing a particular position (Haslam et al.) or are glimpsed in attempts to tighten terms and 
definitions (Atewologun et al.). On rare and special occasions, however, esteemed scholars such as Knights and Clarke undertake to bash heads together in order to point out what is nonsensical in the elaborate language games we construct for ourselves.

We are not, of course, suggesting these are discrete tactics, or that one or other is the way forward. Indeed, Beech's piece can be read as an effort to grapple with the 'gets' of inter-theoretical and for-practice thinking. Beech is not proposing a unifying meta-theory, but does seek to 'get below' and produce an enquiring meta position in which different foundations can make an 'offer' to the enquiry - a way of identifying and framing pertinent questions. It seeks to 'get back' by drawing on different traditions of scholarship which include complementary and incommensurable elements, but it enables a 'getting along' by treating elements as useful questions and insights rather than prescriptive theories. Lastly, in the spirit of Shotter (2006), it is an attempt to 'get with it', or conduct 'withness' dialogue in which the purpose is not to impose change upon the other but to reflexively challenge and develop the self through encounters with the other.

\section{Conclusion: extending further the registers of identity research}

This special issue offers a framework of different registers of identity research to provide a means of locating different theoretical traditions informing different levels of identity research. As a heuristic tool, the framework helps to develop further understanding of the potential for cross-fertilization within and across different levels and theoretical traditions. A number of assumptions about the nature of identity were highlighted as germane to contemporary, identity-informed MOS inquiry. Contrasting assumptions, relating to individual and/or organizational identity as stable-fluid, fixedtemporary/negotiable, coherent-fragmented, singular-multiple, de-contextualizedcontextualized, objective-subjective/intersubjective, independent-dependent, and structurally-agentic determined, may make dialogue and practice difficult both within and across different theoretical traditions. However, this paper and the contributions in the special issue remind us and enable us to see more clearly areas of similarity and difference in identity research. This in itself opens up new possibilities for exploration, and in examining the different 'gets' authors might employ to tackle these divisions we have provided a starting point for debate as much as one for advancing the field(s).

These responses might represent the spectrum of logical responses to the challenges of overcoming the issues of working across registers of identity, but perhaps we are missing something important here. Striving to establish a shared language through which we can know and understand each other, might mean losing the generative potential of engaging with that which remains elusive and problematic, and renders encounters with the diversity of identity scholarship endlessly fascinating. Roland Barthes seminal treatise on the interpretation of texts ' $S / Z$ ' (Barthes, 1974) terms this quality the 'enigma' within narratives. Enticing and 
frustrating in equal measure, it is the enigma of the unfolding textual encounter - that element which remains unexplained, unresolved - that draws the reader to read on to form new understandings of both self and other. Perhaps, then, we should be less anxious to create harmonious accord between registers. Indeed Barthes is critical of such 'readerly' texts that suspend or resolve difference 'equalizing them under the scrutiny of an in-different science, forcing them to rejoin, inductively, the Copy from which we then make them derive' (p. 3). By contrast the defining quality of writerly texts - i.e. those that emerge from 'withness' dialogue - is their elusiveness, raising as many questions as they do provide insight and fresh perspective. For identity scholars, writerly texts bring us into relationship with the otherness of different registers, eliciting both critique and a reflexive questioning of the positions upon which we stand. Perhaps then, as much as the special issue stands as a record of extant research and future directions, its contribution is as a starting point for the more difficult writerly scholarship that reveals new vistas by problematizing the basis of current distinctions.

\section{References}

Academy of Management Review (2000). Special Issue. Organizational identity and identification: Charting new waters and building new bridges, 25, pp. 153-173.

Alvesson, M., Ashcraft, K.L. and Thomas, R. (2008). Identity matters: Reflections on the construction of identity scholarship in organization studies. Organization, 15, pp. $5-28.1$

\section{References}

Academy of Management Review (2000). Special Issue. Organizational identity and identification: Charting new waters and building new bridges, 25, pp. 153-173.

Alvesson, M., Ashcraft, K.L. and Thomas, R. (2008). Identity matters: Reflections on the construction of identity scholarship in organization studies. Organization, 15, pp. 5-28.

Alvesson, M., Hardy, C. and Harley, B. (2008). Reflecting on reflexivity: Reflexive textual practices in organization and management theory. Journal of Management Studies, 45, pp. 480-501.

Atewologun, D., Kutzer, R., Doldor, E., Anderson, D. and Sealy, R. (2017). Individual-level foci of identification at work: A systematic review of the literature. International Journal of Management Reviews, 19, pp. TO BE ADDED BY THE PRODUCTION EDITOR.

Barad, K. (2007). Meeting the universe halfway: Quantum physics and the entanglement of matter and meaning. London: Duke University Press.

Barthes, R. (1974). S/Z, Richard Miller (trans.) New York: Farrar, Straus \& Giroux. 
Braidotti, R. (2013). The posthuman. New York: John Wiley \& Sons.

Brown, A.D. (2017). Identity work and organizational identification. International Journal of Management Reviews, 19, pp. TO BE ADDED BY THE PRODUCTION EDITOR.

Brown, A.D. (2015). Identities and identity work in organizations. International Journal of Management Reviews, 17, pp. 20-40.

Butler, J. (1993). Bodies that matter: On the discursive limits of "sex". New York: Routledge.

Cooper, M. and McLeod, J. (2010). Pluralistic Counselling and Psychotherapy. London: Sage.

Corlett, S., Coupland, C., Mclnnes, P. and Sheep, M. (2015). Call for Papers Special Issue. Exploring the registers of identity research. International Journal of Management Reviews, 17, pp. 409-412.

Corley, K.G., Harquail, C.V., Pratt, M.G., Glynn, M.A., Fiol, C.M. and Hatch, M.J. (2006). Guiding organizational identity through aged adolescence, Journal of Management Inquiry, 15, pp. 85-99.

Cornelissen, J.P., Haslam, S.A. and Balmer, J.M. (2007). Social identity, organizational identity and corporate identity: Towards an integrated understanding of processes, patternings and products. British Journal of Management, 18(s1), pp. S1-S16.

Coupland, C. and Brown, A.D. (2012). Identities in action: Processes and outcomes. Scandinavian Journal of Management, 28, pp.1-4.

Gatrell, C. and Breslin, D. (2017) Editors' statement. International Journal of Management Reviews, 19, DOI: 10.1111/ijmr.12133

Gioia, D.A. (1998). From individual to organizational identity. In Whetten, D.A. and Godfrey, P.C. (eds), Identity in organizations: Building theory through conversations. Thousand Oaks: CA: Sage, pp. 17-32.

Haslam, S.A, Cornelissen, J.P. and Werner, M.D. (2017). Metatheories and Metaphors of Organizational Identity: Integrating Social Constructionist, Social Identity, and Social Actor Perspectives within a Social Interactionist Model. International Journal of Management Reviews, 19, pp. TO BE ADDED BY THE PRODUCTION EDITOR.

Human Relations (2009). Special Issue. Articulating identities, 62, pp. 299-322. Jones, O. and Gatrell, C. (2014). Editorial: The future of writing and reviewing for IJMR. International Journal of Management Reviews, 16, pp. 249-264. 
Knights, D. and Clarke, C. (2017). Pushing the Boundaries of Amnesia and Myopia: A Critical Review ofthe Literature on Identity in Management and Organization Studies. International Journal of Management Reviews, 19, pp. TO BE ADDED BY THE PRODUCTION EDITOR.

Lacan, J. (1980). Ecrits: A selection. London: Tavistock Publications.

Lacan, J. (2008). Os complexos familiares na formação do indivíduo: ensaio de análise de uma função em psicologia. Zahar.

Organization (2008). Special Issue. Identity matters: Reflections on the construction of identity scholarship in organization studies. 15, pp. 5-28.

Pullen, A. and Rhodes, C. (2014). Corporeal ethics and the politics of resistance in organizations. Organization, 21, pp.782-796.

Ravasi, D. and Canato, A. (2013). How do I know who you think you are? A Review of research methods on organizational identity. International Journal of Management Reviews, 15, pp. 185-204.

Scandinavian Journal of Management (2012). Special Issue. Identities in action: Processes and outcomes, 28, pp. 1-4

Shotter, J. (2006) Understanding process from within: An argument for 'withness'thinking. Organization Studies, 27, pp. 585-000

Smith, B. and Sparkes, A.C. (2008). Contrasting perspectives on narrating selves and identities: An invitation to dialogue. Qualitative Research, 8, pp. 5-35.

Suddaby, R. (2010). Editor's comments: Construct clarity in theories of management and organization. Academy of Management Review, 35, pp. 346-357.

Watts, A. (1966). The book: On the taboo against knowing who you are. Pantheon Books.

Weick, K.E. (1979). The Social Psychology of Organizing 2nd Ed. Reading, MA: Addison-Wesley.

Weick, K.E. (1995). Sensemaking in Organizations. London: Sage.

Whetten, D.A. and Godrey, P.C. (eds) (1998). Identity in organizations: Building theory through conversations. Thousand Oaks: CA: Sage.

Winkler, I. (2016). Identity work and emotions: A review. International Journal of Management Reviews, DOI: 10.1111/ijmr.12119

Footnote [i] In presenting key debates as contrasting points on diverging arrows, we appreciate that the framework may reinforce 'false separations' and dominant binary 
thinking which privileges, for instance, mind over body (Knights and Clarke, in this issue). 